\title{
Diabetic neuropathy in the upper limb and the effect of twelve months sorbinil treatment
}

\author{
R.J.C.Guy', S.G.Gilbey ${ }^{1}$, M. Sheehy ${ }^{2}$, P. Asselman ${ }^{2}$ and P.J. Watkins ${ }^{1}$ \\ ${ }^{1}$ Diabetic and ${ }^{2}$ Neurophysiology Department, King's College Hospital, Denmark Hill, London, UK
}

\begin{abstract}
Summary. Clinical and neurophysiological studies were undertaken, with particular reference to the arms, in 39 patients with diabetic neuropathy. The effects of an aldose reductase inhibitor, sorbinil, on neuropathy in these patients were studied in a 12 month double blind placebo controlled trial. Neurophysiological measurements, particularly of sensory amplitude, were considerably more sensitive than measurements of temperature and vibration sensation and remain of fundamental importance in measuring diabetic neuropathy at an early and potentially teversible stage. There was no signifi-
\end{abstract}

cantly beneficial effect of sorbinil on clinical or neurophysiological measurements of nerve function in patients with established diabetic neuropathy. These results indicate that neurophysiological techniques are necessary, in conjunction with clinical measurements, for the assessment of 'early' diabetic neuropathy and that aldose reductase inhibitors are not effective in the treatment of established diabetic neuropathy.

Key words: Diabetic neuropathy, aldose reductase inhibitor, clinical trial.
Polyneuropathy is a common and potentially debilitating complication of diabetes mellitus. The precise cause of diabetic neuropathy is not known. Experimental evidence has suggested a number of possible mechanisms including microvascular disease leading to endoneurial hypoxia [1, 2], glycosylation of nerve proteins [3], and abnormalities of nerve transport [4]. Blood glucose control appears to be of fundamental importance [5] and tight metabolic control may improve nerve function $[6,7]$.

Metabolic abnormalities in diabetic nerve have been extensively investigated. Abnormalities of the polyol pathway in the diabetic nerve lead to sorbitol accumulation [8], in association with myo-inositol depletion [9]. These interrelated abnormalities have been incorporated into a theoretical model centred on nerve $\mathrm{Na} / \mathrm{K}$ ATPase abnormalities [10]. Experimental evidence suggests that abnormalities in diabetic nerves might be reversed by the use of aldose reductase inhibitors leading to reduction of sorbitol levels [11] or by myo-inositol supplementation [12].

Neuropathy does not affect all diabetic patients, varies in its severity and the manner of its presentation, and is difficult to quantify, particularly in its early stages. Biopsy studies have shown both demyelination and axonal degeneration [3]. Neurophysiological abnormalities are often present even in the absence of clinical neuropathy [14]. Thus, measurement is a problem in the assessment of diabetic neuropathy: sensitive neurophysiological measurements may not be specific for diabetic neuropathy, and clinical measurements of sensory thresholds may not be sufficiently sensitive to detect neuropathy at an early stage. Clinically apparent diabetic neuropathy rarely shows spontaneous improvement.

In the present study we compare the results for neurophysiological tests and measurements of sensory thresholds in patients with established diabetic neuropathy and report the results of a double blind placebo controlled study of 12 months treatment with the aldose reductase inhibitor sorbinil. We have examined in particular the upper limb because much less is known regarding diabetic neuropathy in this area and because it is much less severe than in the legs and perhaps more likely to respond to treatment.

\section{Subjects and methods}

\section{Subjects}

Thirty-nine patients with clinical diabetic neuropathy that had been present for at least 6 months were recruited for a 12 month double blind placebo controlled study of treatment with the aldose reduc- 
Table 1. Details of the patients studied

\begin{tabular}{|c|c|c|c|c|c|c|c|c|}
\hline & \multirow{2}{*}{$\begin{array}{l}\text { Age } \\
\text { (years) }\end{array}$} & \multirow{2}{*}{$\begin{array}{l}\text { Diabetes } \\
\text { duration } \\
\text { (years) }\end{array}$} & \multirow{2}{*}{$\begin{array}{l}\text { Diabetes } \\
\text { Type } 1 / \text { Type } 2\end{array}$} & \multicolumn{5}{|l|}{ Number with } \\
\hline & & & & $\begin{array}{l}\text { Pain or } \\
\text { paraesthesia }\end{array}$ & $\begin{array}{l}\text { Foot } \\
\text { ulcers }\end{array}$ & $\begin{array}{l}\text { Autonomic } \\
\text { symptoms }\end{array}$ & $\begin{array}{l}\text { Retino }^{\mathrm{b}} \\
\text {-pathy }\end{array}$ & $\begin{array}{l}\text { Proteinc } \\
\text {-uria }\end{array}$ \\
\hline $\begin{array}{l}\text { Sorbinil } \\
n=21(13 \mathrm{M} / 8 \mathrm{~F})\end{array}$ & $46 \pm 9$ & $21 \pm 11$ & $16 / 5$ & 16 & 8 & 5 & 10 & 5 \\
\hline $\begin{array}{l}\text { Placebo } \\
n=18(9 \mathrm{M} / 9 \mathrm{~F})\end{array}$ & $44 \pm 10$ & $20 \pm 13$ & $13 / 5$ & 12 & 13 & 6 & 13 & 6 \\
\hline
\end{tabular}

Results as mean \pm SD. ${ }^{a}$ diabetic diarrhoea, postural hypotension, or gustatory sweating; ${ }^{b}$ background or proliferative; ${ }^{c}$ persistently albustix positive

tase inhibitor, sorbinil. The following were used as criteria for neuropathy: absent ankle jerks and sensory loss (abnormal vibration and/or temperature sensation) in the feet; typical and severe symptoms of neuropathic pain or paraesthesia as unsolicited complaints on the part of patients with clinical evidence of neuropathy (absent ankle reflexes and/or abnormal temperature or vibration sensation in the foot) [15] and no clinical evidence of peripheral vascular disease (palpable foot pulses or demonstration of an ankle/brachial systolic blood pressure ratio of $>1$ ). Neuropathic pain was defined as typically burning, worse at night, unrelated to exercise and with no other cause (vascular or neurological) being found. All patients were questionned about symptoms of autonomic neuropathy defined as follows: diabetic diarrhoea-intermittent and especially nocturnal diarrhoea, with or without faecal incontinence and with no evidence of other gastrointestinal disease; gustatory sweating - facial sweating precipitated by eating specific foods; postural hypotension - hypotensive symptoms on standing with a drop in systolic blood pressure of over $30 \mathrm{~mm} \mathrm{Hg}$.

Criteria for inclusion in the study were: established diabetes mellitus of over 6 months duration, no change of therapy other than minor dosage changes for the previous 6 months; age less than 60 years. Exclusion criteria were: heavy proteinuria (detected on Albustix testing and found to be in excess of $2 \mathrm{~g} / 24-\mathrm{h}$ urine collection); active liver disease; alternative causes of peripheral neuropathy (e.g. alcohol abuse, thyroid disease, vitamin B12 deficiency); a history of allergy to hydantoin drugs; diabetic mononeuropathy, radiculopathy or amyotrophy; symptomatic nerve entrapment syndromes at the time of consideration for recruitment; symptomatic peripheral vascular disease.

Patients presenting to the diabetic clinic over a 12 month period who fulfilled these criteria were asked to take part in the study. Thus, a heterogeneous group of patients with a wide range of neuropathy were recruited. Table 1 gives clinical details of the patients studied. Fifteen of the patients had a history of neuropathic foot ulceration of whom 6 also had troublesome neuropathic pain, and 22 had as their major complaint symptoms of pain or parasthesiae. Two patients had neither pain nor ulceration but both had severe sensory neuropathy in the feet affecting all modalities and "charcot" neuroarthropathy affecting one foot in one case and troublesome autonomic symptoms in the other. Twenty-nine of the 39 patients (15 males, 14 females; mean $\pm S D$ age $43 \pm 9$ years; duration of diabetes $22 \pm 11$ years) had Type 1 (insulin-dependent) diabetes defined as ketosis-prone, diagnosed under the age of 30 years and insulin treated throughout. Ten patients ( 7 males, 3 females; age $53 \pm$ 5 years; duration of diabetes $13 \pm 9$ years) had Type 2 (non-insulindependent) diabetes defined as diabetes controlled by diet or oral hypoglycaemic agents for 2 years or more following diagnosis, with no history of ketosis or weight loss at the time of diagnosis; 5 of these patients were on insulin and 5 on oral hypoglycaemics. All the patients on insulin were on once or twice daily subcutaneous doses of highly purified pork insulin. No patient was transferred from oral hypoglycaemics to insulin treatment during the study although dosage changes were allowed. No special restrictions were placed on the patients in the study with respect to analgesic or hypnotic treatment of neuropathic pain or insomnia.
One patient dropped out before starting the sorbinil trial. Five patients dropped out during the course of the study; all were female. One patient withdrew from the placebo group with nausea and vomiting which she attributed to the treatment. Four patients withdrew from the treatment group, 3 with symptoms of general malaise and skin irritation, 1 with a hypersensitivity reaction to sorbinil: malaise, erythema, and lymphadenopathy which resolved on stopping treatment. Liver function tests were monitored throughout and no patient showed biochemical evidence of a drug related hepatitis.

Trial design. After a 4 week run-in on placebo capsules supplied by the manufacturer the patients were randomly assigned in a double blind fashion to 52 weeks treatment with either placebo tablets or sorbinil $250 \mathrm{mg}$ (Pfizer Central Research, Sandwich, Kent, UK) [16] once daily. Major assessments of neuropathy were performed at -4 (when randomisation was undertaken), 0,24 and 52 weeks, with reviews at 4 to 8 week intervals to check for side effects and measurement of glycosylated haemoglobin $\left(\mathrm{HBA}_{1}\right)$ by electroendosmosis (Corning Ltd, Halstead, Essex, UK), liver function tests, haemotological indices, and compliance (by tablets counts). The trial was approved by the hospital ethical committee and all patients gave informed consent.

\section{Methods}

All clinical assessments were undertaken by one of two investigators. Nerve conduction studies and measurement of somatosensoryevoked potentials were performed by the same investigators throughout.

Clinical examination. This consisted of a detailed history and clinical examination at the time of recruitment and at each major visit with special emphasis on the peripheral nervous system.

Measurement of sensation. Two-point discrimination was measured on the pulp of the dominant index finger using a pair of dividers and expressed in millimetres. Temperature and vibration sensation were measured in the dominant hand and foot using established techniques. Temperature sensation was measured on the thenar eminence of the hand and on the foot immediately below the lateral malleolus using a Marstock device (Somedic, Stockholm, Sweden [17]) and expressed as the warm-cool difference in degrees centigrade. Vibration sensation was measured on the index finger and hallux using a hand-held biothesiometer (Biomedical Instruments, Newbury, Ohio, USA) and expressed in volts [18]. Previous work in this department has established the reproducibility of these techniques and a normal range for subjects under the age of 55 years [15].

Autonomic function testing. A Lectromed instantaneous heart rate meter, MX2P amplifier, and MX212 chart recorder (Lectromed, St. Quen, Jersey, Channel Islands), were used to measure heart rate variation on deep breathing [19], heart rate increase on standing, and the response to a standard valsalva manoeuvre [20]. Blood pressure change on standing was measured using a standard mercury sphygmomanometer.

Neurophysiology. The dominant arm and leg were used. The limb was warmed if necessary to give a skin temperature of $34^{\circ} \mathrm{C}$. The 
Table 2. Neurophysiological measurements

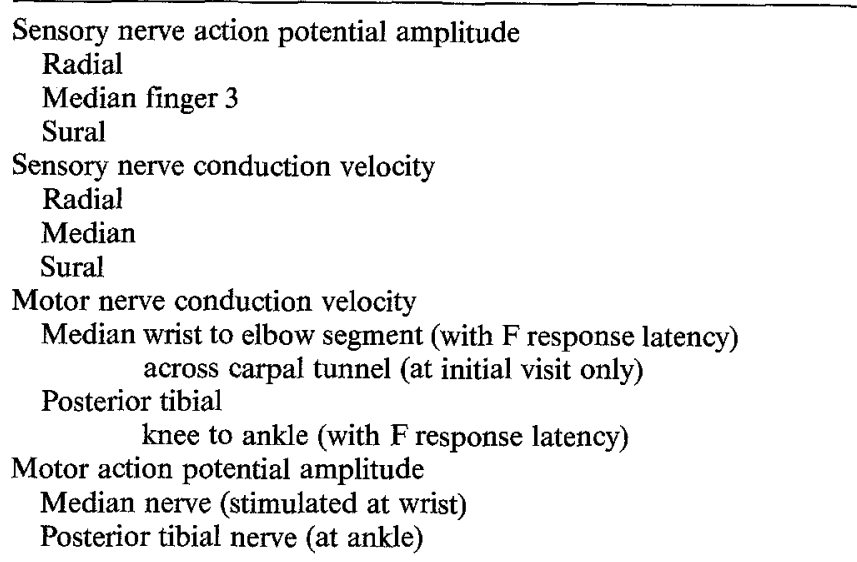

Table 3. Diabetic control: $\mathrm{HBA}_{1}$ levels throughout sorbinil study

\begin{tabular}{llll}
\hline & Baseline & 6 months & 12 months \\
\hline Sorbinil & $11.0 \pm 1.9$ & $11.0 \pm 2.1$ & $10.6 \pm 1.4$ \\
Placebo & $12.1 \pm 2.3$ & $12.8 \pm 2.6$ & $12.1 \pm 2.4$ \\
\hline
\end{tabular}

Results as mean $\pm \mathrm{SD}$. Units are $\%$ glycosylation of haemoglobin. Normal value $<8 \%$

Table 4. Comparison of temperature sensation, vibration threshold, and autonomic function tests

\begin{tabular}{lllll}
\hline & $\begin{array}{l}\text { Vibration } \\
\text { hand }\end{array}$ & $\begin{array}{l}\text { Temperature } \\
\text { hand }\end{array}$ & $\begin{array}{l}\text { Vibration } \\
\text { foot }\end{array}$ & HRV $^{\mathrm{a}}$ \\
\hline Temperature & 0.96 & 0.43 & 0.46 & -0.16 \\
hand & $p<0.0001$ & $p<0.006$ & $p<0.005$ & $\mathrm{NS}$ \\
Vibration & & 0.44 & 0.56 & -0.27 \\
hand & & $p<0.005$ & $p<0.0005$ & $\mathrm{NS}$ \\
Temperature & & & 0.66 & -0.43 \\
foot & & $p<0.0005$ & $p<0.006$ \\
Vibration & & & & -0.6 \\
foot & & & & $p<0.0005$ \\
\hline
\end{tabular}

Results shown as correlation coefficients.

${ }^{\text {a }}$ Heart rate variation

skin was cleaned and abraded to lower resistance if necessary. An earth electrode was always placed between stimulating and recording sites. Twelve neurophysiological parameters ( 7 in the arm, 5 in the leg) were measured using a MEDELEC MS6 (Medelec, Woking, Surrey, UK) recording system (Table 2). 95\% confidence intervals of results from normal control subjects in this laboratory were used as a normal range.

Somatosensory-evoked potentials. Somatosensory-evoked potentials were measured for both upper limbs using a Digitimer D200 (Digitimer Welwyn Garden City, Herts., UK) signal analyser system. The response to supramaximal stimulation of the median nerve was measured by recording electrodes at 3 levels: over Erb's point, the second cervical vertebra, and the hand area of the contralateral sensory cortex (at a point $2 \mathrm{~cm}$ behind and $7 \mathrm{~cm}$ down from the vertex parallel to a line from the vertex towards the tragus). The average of at least 256 sweeps was used to measure peak to peak amplitude and latency to peaks at all 3 levels, a total of 6 measurements at each visit.

\section{Statistical analysis}

No significant differences were found between values for weeks -4 and 0 and the results for these two visits were averaged to give a

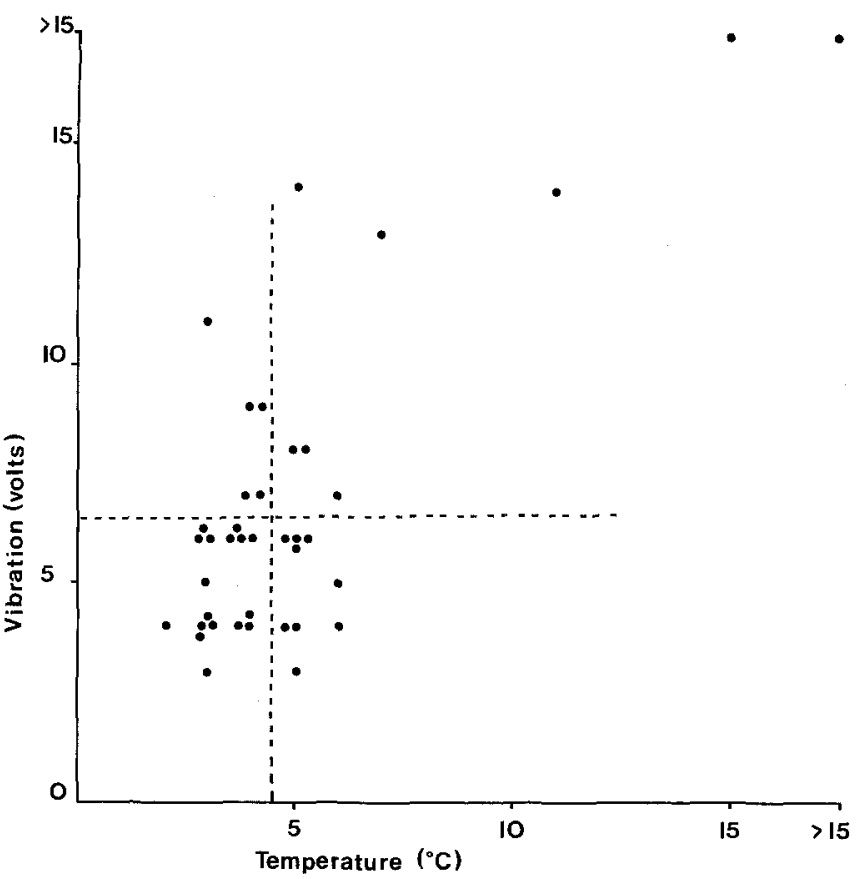

Fig. 1. Comparison of temperature and vibration sensation in the hand. Dotted lines indicate upper $95 \%$ confidence limits of normal. There was a highly significant correlation between the two measurements $(r=0.96 ; p<0.0001)$

baseline value. Mean values at times 0,6 , and 12 months were calculated for each of the 27 variables measured and the mean change in each variable across the 12 month period calculated. The statistical significance of the change recorded in each variable was calculated using a Wilcoxon rank sum test on the individual patient changes (with normal approximation and a continuity correction). An average rate of change for each patient was also calculated using a least squares regression coefficient and the significance of this change for the treatment and placebo groups respectively was derived by performing a Wilcoxon rank sum test. The results from both tests were very similar. $p$ values from the latter test only are quoted in Table 3. Correlation coefficients were used for comparison of cross-sectional data. The level of significance was taken as $p<0.05$.

\section{Results}

\section{Neuropathy in the upper limb}

Temperature and vibration sensation. Temperature and vibration sensations in the hand showed a high degree of correlation with each other $(r=0.96 ; p<0.0001$; Fig.1) and weaker but still significant correlations with sensory thresholds in the foot (Table 4).

Temperature and vibration sensation and autonomic function. Our results indicate that vagal function is affected before temperature sensation in the hand: 10 out of 39 patients had abnormal heart rate variation (HRV) but normal hand temperature sensation, and only 2 patients abnormal temperature sensation with a normal HRV. Temperature and vibration sensation in the foot showed highly significant correlations with HRV $(r=0.43, p<0.006 ; r=0.56, p<0.0005$, respectively), suggesting that vagal damage was occurring at 


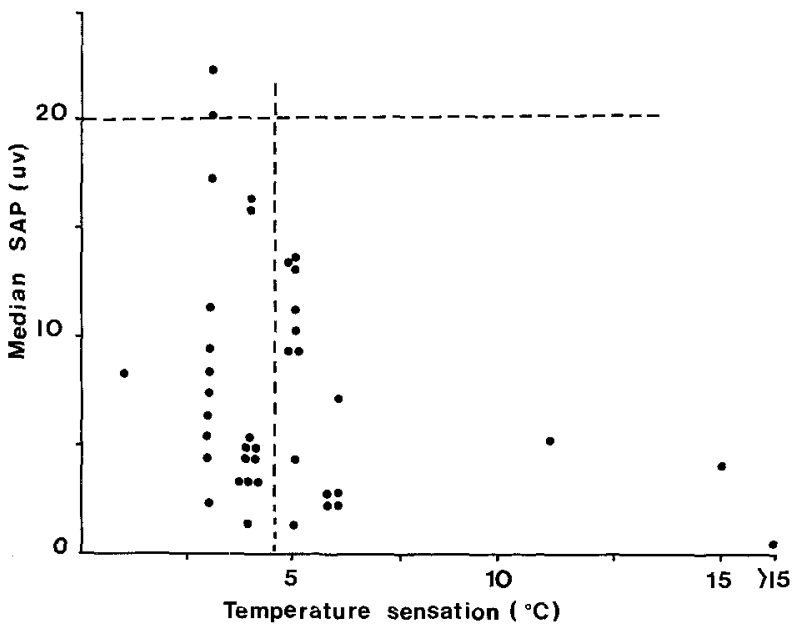

Fig. 2. Comparison of temperature sensation in the hand and median nerve sensory action potential (SAP). Dotted lines indicate the upper $95 \%$ confidence limit of normal for temperature sensation and the lower limit of normal for median SAP. $r=0.30(\mathrm{NS})$

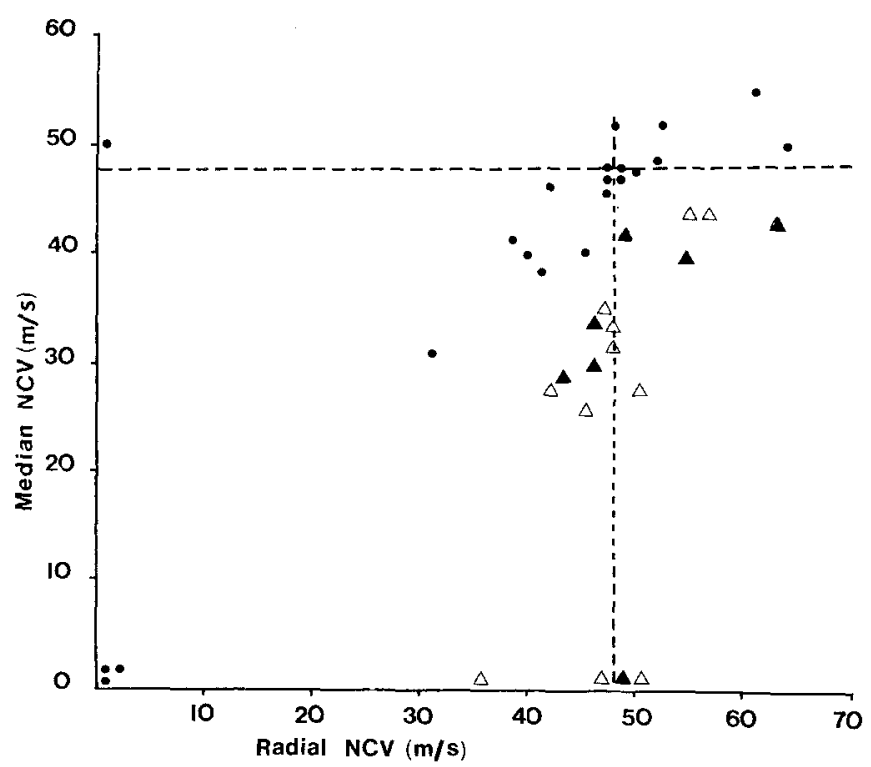

Fig. 3. Evidence for carpal tunnel compression. Median nerve conduction velocity (NCV) across the carpal tunnel against radial sensory nerve conduction velocity. Dotted lines indicate lower limits of normal. \& represent patients with disproportionate slowing of median nerve conduction. $\Delta$ represent patients who have in addition thenar muscle action potential latency $\geq 4 \mathrm{~ms}$

Table 5. Comparison of clinical and neurophysiological measurements

\begin{tabular}{|c|c|c|c|c|c|c|c|}
\hline & $\begin{array}{l}\text { Median } \\
\text { SAP }\end{array}$ & $\begin{array}{l}\text { Post tib } \\
\text { NCV }\end{array}$ & $\begin{array}{l}\text { Temp. } \\
\text { hand }\end{array}$ & $\begin{array}{l}\text { Temp. } \\
\text { foot }\end{array}$ & $\begin{array}{l}\text { Vib. } \\
\text { hand }\end{array}$ & $\begin{array}{l}\text { Vib. } \\
\text { foot }\end{array}$ & HRV \\
\hline $\begin{array}{l}\text { Radial } \\
\text { SAP }\end{array}$ & $\begin{array}{l}0.55 \\
p=0.0003\end{array}$ & $\begin{array}{l}0.57 \\
p=0.00\end{array}$ & $\begin{array}{c}-0.34 \\
2 p=0.03\end{array}$ & $\begin{array}{l}-0.5 \\
p=0.0009\end{array}$ & $\begin{array}{c}-0.32 \\
9 p=0.04\end{array}$ & $\begin{array}{l}0.64 \\
p=0.0001\end{array}$ & $\begin{array}{c}0.45 \\
1 p=0.004\end{array}$ \\
\hline Median & & 0.43 & -0.3 & -0.34 & 0.32 & 0.54 & 0.53 \\
\hline SAP & & $p=0$ & & $p=0.03$ & $p=0.04$ & $p=0.0005$ & $5 p=0.0006$ \\
\hline Post tib & & & -0.09 & -0.53 & -0.09 & -0.53 & 0.45 \\
\hline & & & NS & $p=0.00071$ & & $p=0.0007$ & \\
\hline
\end{tabular}

All results shown as correlation coefficients. SAP: Sensory-action potential; NCV: Nerve conduction velocity; Vib.: Vibration threshold; Temp.: Temperature sensation a similar stage in the development of diabetic neuropathy as abnormal sensation in the foot and before abnormal sensation in the hand.

\section{Neurophysiological measurements}

Results for neurophysiological measurements were compared to established normal ranges in this laboratory. There was a high prevalence of abnormal neurophysiological findings and in particular sensory measurements. Thus, 37 out of 39 patients had median sensory action potential (SAP) values of less than $20 \mu \mathrm{V}$ (mean \pm SD $7.1 \pm 5.4 \mu \mathrm{V}$ ) and $34 / 39$ radial SAP values $\angle 20 \mu \mathrm{V}(10.2 \pm 9.0 \mu \mathrm{V})$. There was a significant correlation between median and radial SAP $(r=0.55$; $p=0.003$ ).

Temperature and vibration sensation and neurophysiological tests. A much higher proportion of patients showed abnormal neurophysiological tests in the arms, particularly median and radial SAP, than had abnormal vibration or temperature sensation in the hand. Figure 2 illustrates this, showing that median sensory action potential is a more sensitive measure of abnormality in the arm than temperature sensation: 2 out of 39 patients had normal values for both measurements, 4 patients had abnormal values for both measurements, and 33 had normal temperature sensation but abnormal median SAP. No patient showed normal median SAP with abnormal temperature sensation. Other comparisons between sensation and neurophysiological measurements in the arm showed the same pattern. No simple correlation existed between neurophysiological tests in the arm and temperature and vibration sensation in the hand. In contrast, measurements of sensory action potential in the arms correlated closely with both temperature and vibration sensation in the foot (see Table 5).

\section{Somatosensory-evoked potentials}

In 3 of the 39 patients somatosensory-evoked potentials (SEP) responses could not be measured for technical reasons. Seventeen out of the remaining 36 patients had evidence of delayed conduction $(>22 \mathrm{~m} / \mathrm{s}$ from hand to contralateral sensory cortex). A striking feature of the SEP measurements was their poor correlation with other neurophysiological measurements. The only statistically significant association found was between SEP latency to the axilla and motor nerve conduction velocity in the median $(r=-0.565$; $p=0.003)$ and posterior tibial $(r=-0.581 ; p=0.002)$ nerves.

\section{Carpal tunnel compression}

The presence or history of symptomatic carpal tunnel compression excluded patients from this study. Neurophysiological evidence for carpal tunnel compression 
includes slowing of median motor nerve conduction across the carpal tunnel (normal $>48 \mathrm{~m} / \mathrm{s}$ ), and delay $(>4 \mathrm{~m} / \mathrm{s})$ of the evoked surface recorded thenar muscle action potential following stimulation of the median nerve at the wrist [21]. The results showed a high prevalence of asymptomatic carpal tunnel compression: 18 out of 39 patients showed slowing of median nerve conduction velocity across the carpal tunnel (normal $>48 \mathrm{~m} / \mathrm{s}$ ) together with normal radial sensory nerve conduction (Fig.3). Eleven of these 18 patients also had delay of the thenar muscle action potential as confirmatory evidence of carpal tunnel compression.

\section{Neuropathy and diabetic control}

There was no association between any of the measurements made in hand or foot and diabetic control at the time of testing as measured by $\mathrm{HBA}_{1}$ concentration.

\section{Sorbinil trial}

None of the measurements made, whether in the hand or foot, showed any statistically significant beneficial effect of sorbinil. Table 2 gives details of the neurophysiological measurements made.

\section{Diabetic control}

Blood glucose control as assessed by $\mathrm{HBA}_{1}$ levels was similar in both groups throughout the study (Table 3 ).

\section{Clinical assessment}

No patient showed an overall improvement in his or her neuropathy as judged by clinical examination during the period of study. Patients with painful symptoms or paraesthesiae were asked at the end of the trial to make a purely subjective assessment as to whether their symptoms had changed over the course of the study. Seven out of 12 patients on Sorbinil who had symptoms of pain or parasthesia at the onset of the study reported that their symptoms had improved, compared to 3 out of 12 on placebo $(p=0.053)$.

\section{Temperature and vibration sensation}

Table 6 shows the results of sensory tests in the arm. The heterogeneous nature of the patients studied resulted in a wide range of results. There was no statistically significant difference between the two groups in any of the measurements made.

\section{Autonomic function tests}

There was no statistically significant difference between the two groups for any of the measurements made. Results for heart rate variation are shown in Table 6.
Table 6. Results for the Sorbinil trial. Heart rate variation and measurements in the upper limb

\begin{tabular}{|c|c|c|c|c|c|}
\hline \multirow{2}{*}{$\begin{array}{l}\text { Variable } \\
\text { (normal) }\end{array}$} & \multicolumn{2}{|l|}{ Baseline } & \multicolumn{2}{|c|}{12 months } & \multirow[t]{2}{*}{$p$} \\
\hline & placebo & sorbinil & placebo & sorbinil & \\
\hline $\begin{array}{l}\text { Heart rate } \\
\text { variation } \\
(>12 \text { beats } / \mathrm{min})\end{array}$ & $9.3 \pm 7.5$ & $10.7 \pm 8.1$ & $7.3 \pm 6.0$ & $10.0 \pm 9.0$ & 0.75 \\
\hline $\begin{array}{l}\text { Vibration } \\
\text { threshold } \\
(<6.3 \mathrm{~V})\end{array}$ & $8.0 \pm 7.0$ & $7.5 \pm 5.0$ & $8.3 \pm 4.7$ & $7.0 \pm 3.0$ & 0.40 \\
\hline $\begin{array}{l}\text { Temperature } \\
\text { sensation }{ }^{\mathrm{a}} \\
\left(<4.5^{\circ} \mathrm{C}\right)\end{array}$ & $5.4 \pm 5.2$ & $5.3 \pm 2.8$ & $4.9 \pm 3.1$ & $5.2 \pm 2.4$ & 0.05 \\
\hline $\begin{array}{l}2 \text { point } \\
\text { discrimination } \\
(\mathrm{mm})\end{array}$ & $3.6 \pm 0.7$ & $3.4 \pm 0.8$ & $3.5 \pm 0.7$ & $3.3 \pm 0.6$ & 0.46 \\
\hline $\begin{array}{l}\text { SEP latency } \\
\text { to cortex } \\
(<20.02 \mathrm{~ms})\end{array}$ & $21.7 \pm 1.3$ & $21.2 \pm 1.4$ & $21.6 \pm 1.2$ & $21.2 \pm 1.5$ & 0.22 \\
\hline Median nerve & $35.4 \pm 5.1$ & & $34.5 \pm 4.6$ & & \\
\hline $\begin{array}{l}\text { F response } \\
(<30 \mathrm{~ms})\end{array}$ & & $33.4 \pm 3.3$ & & $33.0 \pm 3.2$ & 0.85 \\
\hline Median & $44.1 \pm 6.2$ & & $44.6 \pm 7.0$ & & \\
\hline $\begin{array}{l}\text { motor NCV } \\
(>48 \mathrm{~m} / \mathrm{s})\end{array}$ & & $46.5 \pm 5.9$ & & $49.3 \pm 5.6$ & 0.13 \\
\hline $\begin{array}{l}\text { Median mixed } \\
\text { NCV } \\
(>48 \mathrm{~m} / \mathrm{s})\end{array}$ & $52.3 \pm 4.3$ & $56.0 \pm 4.3$ & $54.3 \pm 4.5$ & $60.2 \pm 6.0$ & 0.69 \\
\hline $\begin{array}{l}\text { Median } \\
\text { (finger 3) } \\
\text { SAP } \\
(>20 \mu \mathrm{V})\end{array}$ & $6.9 \pm 4.7$ & $7.7 \pm 6.2$ & $7.6 \pm 5.0$ & $9.1 \pm 6.8$ & 0.34 \\
\hline Radial & $11.2 \pm 6.9$ & $11.2 \pm 9.9$ & $9.6 \pm 4.4$ & $14.4 \pm 10.0$ & 0.20 \\
\hline $\begin{array}{l}(>20 \mu \mathrm{V}) \\
\text { Radial } \\
\text { sensory NCV } \\
(>48 \mathrm{~m} / \mathrm{s})\end{array}$ & $47.4 \pm 6.4$ & $49.9 \pm 7.9$ & $47.0 \pm 4.9$ & $52.7 \pm 9.5$ & 0.12 \\
\hline
\end{tabular}

NCV: nerve conduction velocity SAP: sensory action potential, SEP: somatosensory evoked potential. ${ }^{\mathrm{a}}$ in the hand; $p$ values derived by Wilcoxon rank sum test. $\mathrm{m} / \mathrm{s}$ : metres per second; $\mathrm{ms}$ : milliseconds

\section{Nerve conduction and somatosensory-evoked potentials}

Twelve nerve conduction and 6 somatosensory-evoked potential variables were measured. None showed any statistically significant beneficial effect of sorbinil compared to placebo. Table 6 gives details of some of the results for measurements in the arms.

\section{Discussion}

This study of diabetic neuropathy shows firstly, that electrophysiological measurements are more sensitive in detecting neuropathy than clinical sensory tests of thermal and vibration thresholds and secondly, that administration of an aldose reductase inhibitor for 12 months is not of benefit in established neuropathy affecting either the legs or the arms (where it is less severe). It is not yet clear whether very early neuropathy 
responds to administration of aldose reductase inhibitors.

A wide variety of techniques may be used to assess neuropathy. Small fibres appear to be affected early in the course of the disease and, since microneurography [22] is not generally available, function was assessed by measuring thermal sensation and autonomic function. Our results show, however, that sensory thresholds are much less sensitive in detecting early neuropathy than neurophysiological measurements, notably sensory action potentials which reflect at least in part slowing of nerve conduction in large myelinated fibres with temporal dispersion of the sensory potential [23]. These neurophysiological measurements can be affected by diabetic control [24] but almost certainly reflect the existence of neuropathy; measurements in the arm correlate well with sensory defects in the feet. Thus they are early indicators of neuropathy and their serial measurement is of great importance in a study of this kind, especially when they are combined with clinical measurements of sensory thresholds.

Diabetic neuropathy in the upper limb is less severe than in the lower limb, and distal segments of nerves are affected before proximal segments $[14,23]$. This is generally attributed to the increased vulnerability of longer nerves [25]. For these reasons the assessment of neuropathy in this study has involved a particular emphasis on the relatively less severely involved upper limbs, which might be expected to be more responsive to treatment. Interpretation of median nerve function must, however, be circumspect, since neurophysiological evidence of carpal tunnel compression is shown here to be extremely common even when patients with clinically apparent features have been excluded.

Published clinical trials of aldose reductase inhibitors in neuropathy have involved treatment for up to 6 months. Very small effects on nerve conduction in asymptomatic patients [26] and some improvement of autonomic function have been reported [27], although in many instances there have been no demonstrable changes in nerve function. Relief of pain [28] and paraesthesia [29] has been described; this has not been reproduced in other studies [30] and more detailed investigation is required. The present study describes the use of sorbinil for 12 months and is among the largest trials reported so far. No statistically significant effect could be demonstrated on any of a wide variety of measurements of nerve function whether sensory or motor, and involving both small and large nerve fibre function. The measurements made included neurophysiological studies, autonomic function tests, and, for the first time, sensory-evoked potentials and sensory evaluation of thermal and vibration thresholds.

A striking feature of the patients in this study as a group was their disappointingly poor metabolic control before and during the study as shown by glycosylated haemoglobin values. This is in keeping with the prevailing belief that poor metabolic control over a period of years renders patients more susceptible to neuropathy and other diabetic complications [31]. It also begs the question as to whether good metabolic control is more difficult to achieve in patients with neuropathy than in diabetic patients without complications. Several studies have suggested that intensive insulin therapy leading to improved metabolic control is of value in the treatment of patients with neuropathy, symptomatic or otherwise [5-7, 32]. However, just as with aldose reductase inhibitors, prospective studies of patients with no discernible evidence of neuropathy or at a very early stage of neuropathy may be necessary to provide a definitive answer to this important question.

There is, therefore, now ample evidence that aldose reductase inhibitors do not have a major beneficial effect on established diabetic neuropathy even when, as in the present study, the arms rather than the more severely affected legs have been examined. Whether treatment with aldose reductase inhibitors much earlier in the course of diabetes might be valuable remains to be evaluated. Clearly, future work needs to be directed to patients with little if any evidence of neuropathy. Demonstration of a clinical effect in such patients would be of the greatest importance in understanding the pathogenesis of diabetic neuropathy and would also have important clinical implications. We conclude, however, that aldose reductase inhibitors are unlikely to be of value in the treatment of established diabetic neuropathy.

Acknowledgements. We gratefully acknowledge Pfizer Central Research, Sandwich, Kent, UK, for their help with the trial, and Pfizer Inc. for financial support for RJCG.

\section{References}

1. Dyck PJ, Hansen S, Karnes J, O'Brien P, Yasuda H, Windebank A, Zimmerman B (1985) Capillary number and percentage closed in human diabetic sural nerve. Proc Natl Acad Sci USA 82: 2513-2517

2. Tuck RR, Schmelzer JD, Low PA (1984) Endoneurial blood flow and oxygen tension in the sciatic nerve of rats with experimental diabetic neuropathy. Brain 107: 935-950

3. Vlassara H, Brownlee M, Cerami A (1983) Excessive nonenzymatic glycosylation of peripheral and central nervous system myelin components in diabetic rats. Diabetes 32: 670-674

4. Tomlinson DR, Mayer JH (1984) Defects of axonal transport in diabetes mellitus - a possible contribution to the aetiology of diabetic neuropathy. J Auton Pharmacol 4: 59-57

5. Gregersen G (1967) Diabetic neuropathy: influence of age, sex, metabolic control, and duration of diabetes on motor conduction velocity. Neurology (Minneapolis) 17: 972-980

6. Pietri A, Ehle AL, Raskin $P(1980)$ Changes in nerve conduction velocity after six weeks of glucoregulation with portable insulin infusion pumps. Diabetes 29: 668-671

7. Service FJ, Rizza RA, Daube JR, O'Brien PC, Dyck PJ (1985) Near normoglycaemia improved nerve conduction and vibration sensation in diabetic neuropathy. Diabetologia 28: 722-727

8. Gabbay KH, Merola LO, Field RA (1966) Sorbitol pathway: presence in nerve and cord with substrate accumulation in diabetes. Science 151: 209-210 
9. Finegold D, Lattimer SA, Nolle S, Bernstein M, Greene DA (1983) Polyol pathway activity and myo-inositol metabolism: a suggested relationship in the pathogenesis of diabetic neuropathy. Diabetes 32: 988-992

10. Greene DA, Lattimer S, Ulbrecht J, Carroll P (1985) Glucose-induced alterations in nerve metabolism: current perspective on the pathogenesis of diabetic neuropathy and future directions for research and therapy. Diabetes Care 8: 290-299

11. Greene DA (1983) Metabolic abnormalities in diabetic peripheral nerve: relationship to impaired function. Metabolism 32: 118-123

12. Greene DA, DeJesus PV, Winegrad AI (1975) Effects of insulin and dietary myo-inositol on impaired peripheral motor nerve conduction velocity in acute streptozotocin diabetes. J Clin Invest $55: 1326-1336$

13. Thomas PK (1984) Diabetic Neuropathy. In: Dyck PJ, Thomas PK, Lambert EH, Bunge RP (eds) Peripheral Neuropathy, 2nd edn. WB Saunders, Philadelphia, pp 1773-1810

14. Noël P (1973) Sensory nerve conduction in the upper limbs at various stages of diabetic neuropathy. J Neurol Neurosurg Psychiatry $36: 786-796$

15. Guy RJC, Clark CA, Malcolm PN, Watkins PJ (1985) Evaluation of thermal and vibration sensation in diabetic neuropathy. Diabetologia $28:$ 131-137

16. Peterson MJ, Sarges R, Aldinger CE, MacDonald DP (1979) CP-45, 634: a novel aldose reductase inhibitor that inhibits polyol pathway activity in diabetic or galactosemic rats. Metabolism 28 [Suppl 1]: 456-461

17. Fruhstorfer H, Lindblom U, Schmidt WG (1976) Method for quantitative estimation of thermal thresholds in patients. J Neurol Neurosurg Psychiatry 39: 1071-1075

18. Steiness IB (1957) Vibratory perception in normal subjects. A biothesiometric study. Acta Med Scand 158: 315-325

19. McKay JD, Page MMcB, Cambridge J, Watkins PJ (1980) Diabetic autonomic neuropathy. The diagnostic value of heart rate monitoring. Diabetologia 18: 471-478

20. Levin $A B$ (1966) A simple test for cardiac function based upon the heart rate changes induced by the valsava manoeuvre. Am J Cardiol 18: 90-99

21. Simpson JA (1956) Electrical signs in the diagnosis of carpal tunnel and related syndromes. J Neurol Neurosurg Psychiatry 19: 275-280

22. Fagius J (1982) Microneurographic findings in diabetic polyneuropathy with special reference to sympathetic nerve activity. Diabetologia $23: 415-420$
23. Lamontagne A, Buchthal F (1970) Electrophysiological studies in diabetic neuropathy. J Neurol Neurosurg Psychiatry 33: 442-452

24. Ward JD, Barnes CG, Fisher DJ, Jessop JD (1971) Improvement in nerve conduction following treatment in newly diagnosed diabetics. Lancet I: 428-431

25. Waxman SG (1983) Pathophysiology of nerve conduction: relation to diabetic neuropathy. Ann Int Med 92: 297-301

26. Judzewitch RG, Jaspan JB, Polonsky KS, Weinberg CR, Halter JB, Halar E, Pfeifer MA, Vukadinovic C, Bernstein L, Schneider M, Liang KY, Gabbay KH, Rubenstein AH, Porte J Jr (1983) Aldose reductase inhibition improves nerve conduction velocity in diabetic patients. N Engl J Med 308: 119-125

27. Fagius J, Jameson S (1981) Effects of aldose reductase inhibitor treatment in diabetic polyneuropathy - a clinical and neurophysiological study. J Neurol Neurosurg Psychiatry 44: 991-1001

28. Jaspan J, Maselli R, Herold K, Bartkus C (1983) Treatment of severely painful diabetic neuropathy with an aldose reductase inhibitor: relief of pain and improved somatic and autonomic function. Lancet II: 758-762

29. Shand DG and the Tolrestat painful neuropathy study group (1986) The efect of Tolrestat, a new aldose reductase inhibitor, on nerve conduction and painful symptoms in diabetic neuropathy. Diabetic Medicine 3: 559 (Abstract)

30. Lewin IG, O'Brien IAD, Morgan MH, Corrall RJM (1984) Clinical and neurophysiological studies with the aldose reductase inhibitor, sorbinil, in symptomatic diabetic neuropathy. Diabetologia 26: $445-448$

31. Pirart J (1978) Diabetes mellitus and its degenerative complications: a prospective study of 4,400 patients observed between 1947 and 1973. Diabetes Care 1: 168-176

32. Boulton AJM, Drury J, Clarke B, Ward JD (1982) Continous subcutaneous infusion in the management of painful diabetic neuropathy. Diabetes Care 5: 386-391

Received: 23 November 1987

and in revised form: 3 February 1988

Dr. P.J. Watkins

Diabetic Department

Kings College Hospital

Denmark Hill

London SE5 9RS

UK 